\title{
Hemodynamic evaluation of elderly patients during laparoscopic cholecystectomy
}

\section{Avaliação hemodinâmica de pacientes idosos durante colecistectomia vídeo- laparoscópica}

Luiz Paulo Jacomell Ramos, tCbC-RJ1; Rodrigo Barcellos Araújoz; Maria do Carmo Valente Castro3; Maria Roberta Meneguetti Seravalli Ramos"; José Antonio Cunha-e-Silva; Antonio Carlos Iglesias, ECBC-RJ1

\section{A B S T R A C T}

\begin{abstract}
Objective: to demonstrate hemodynamic changes during laparoscopic cholecystectomy in elderly patients with trans-esophageal echocardiography. Methods: we studied 31 elderly patients (aged 60 years or older), ASA I or II, who underwent elective laparoscopic cholecystectomy under general, standardized anesthesia, with cardiovascular parameters measured using transesophageal echocardiography at three different times: before the pneumoperitoneum (T1), after CO2 insufflation (T2) and at deflation (T3). We statistically evaluated changes in systolic, diastolic and mean blood pressure, heart rate, cardiac output and index, and ejection fraction. Results: although small, only the diastolic blood pressure (DBP) and ejection fraction (EF) variations were statistically significant. The mean \pm standard deviation of $D B P$ in $\mathrm{mmHg}$ at the different times were: $T 1=67.5 \pm 10.3 ; T 2=73.6 \pm 12.4$; and $T 3=66.7 \pm 9.8$. And for $E F$, in percentage (\%) they were: $T 1=66.7 \pm 10.4 ; T 2=63.2 \pm 9.9$; and $T 3=68.1 \pm 8.4$. There was no statistical correlation between hemodynamic variations, age and number of patients' comorbidities. Conclusion: laparoscopic cholecystectomy causes few hemodynamic changes that are well tolerated by the majority of the elderly patients; prior impairment of ventricular function represents a threat in elderly patients during surgery; there appears to be a lower hemodynamic effect caused by the pneumoperitoneum than by the patient's positioning in a reverse Trendelemburg during surgery.
\end{abstract}

Keywords: Blood Pressure. Hemodynamics. Echocardiography, Transesophageal. Aged. Laparoscopy. Pneumoperitoneum, Artificial.

\section{INTRODUCTION}

holelithiasis is the most common surgical abdominal disease of the elderly, with a prevalence of $21.4 \%$ between 60 and 69 years and $27.5 \%$ in individuals older than 70 years ${ }^{1}$. The increase in life expectancy associated with a higher incidence of cholelithiasis in the elderly has resulted in a greater number of surgeries for the treatment of symptomatic disease in this group2. Laparoscopic cholecystectomy (LC) is currently the procedure of choice for the treatment of cholelithiasis, and is used very often even in the elderly, with comparable efficacy to the young population ${ }^{1-6}$.

Although several studies have evaluated the hemodynamic changes due to pneumoperitoneum, the mechanisms involved in cardiovascular variations have not yet been fully elucidated. Works have been carried out in groups of non-homogeneous patients, under different intra-abdominal pressures and with different positions during surgery ${ }^{7-9}$.

This study aims to demonstrate the hemodynamic changes resulting from the pneumoperitoneum in elderly patients submitted to LC and monitored with transesophageal echocardiography (TEE).

1 - Federal University of the State of Rio De Janeiro, Service of General and Digestive System Surgery, Rio de Janeiro, RJ, Brazil. 2 - Federal University of the State of Rio De Janeiro, Anesthesiology Service, Rio de Janeiro, RJ, Brazil. 3 - Federal University of the State of Rio de Janeiro, Cardiology Service, Rio de Janeiro, RJ, Brazil. 4 - Evandro Chagas National Institute of Infectology/FIOCRUZ, Clinical Research Laboratory, Rio de Janeiro, RJ, Brazil. 


\section{METHODS}

Thirty-one elderly patients with cholelithiasis, aged 60 years or older, diagnosed by abdominal ultrasonography at the Gaffrée and Guinle University Hospital (HUGG) over two years were submitted to elective LC and monitored with trans-esophageal echocardiography during the procedure.

We included in the study the elderly classified as ASA I or II (American Society of Anesthesiologist), after signing the informed consent form, and with prior authorization from the HUGG Ethics in Research Committee under the protocol number 11607913600005258. We excluded patients with significant esophageal or cardiovascular diseases, as well as those who presented absolute contraindications to TEE. We also excluded those with acute cholecystitis.

All patients underwent standardized general anesthesia, with continuous monitoring. Anesthetic induction was done with Fentanyl $4 \mathrm{mcg} / \mathrm{kg}$, Propofol $2 \mathrm{mg} /$ $\mathrm{kg}$ and Atracurium $0.5 \mathrm{mg} / \mathrm{kg}$ after pre-oxygenation with $100 \%$ oxygen for three minutes. Oro-tracheal intubation (OTI) was performed two to three minutes after the muscle relaxant. Anesthesia maintenance was performed with Sevorane.

The patients were ventilated under volume controlled ventilation (VCV) mode, with a parameter programmed for total volume of $7 \mathrm{ml} / \mathrm{kg}$ (eg VCV $=490 \mathrm{ml}$ in a $70 \mathrm{~kg}$ person), respiratory frequency (RF) of 12 , positive end expiratory pressure (PEEP) of $5 \mathrm{cmH}_{2} \mathrm{O}$, which is physiological PEEP, and peak of $40 \mathrm{cmH}_{2} \mathrm{O}$, with an inspiratory/expiratory ratio (I:E) of 1:2.

All patients were monitored with continuous electrocardiogram, pulse oximeter and capnography. Automatic systemic blood pressure measurement triggered every five minutes. These parameters were recorded after OTI, during the pneumoperitoneum and during the TEE study.

We installed the pneumoperitoneum with a Veress needle and maintained it by continuous insufflation of carbon dioxide $\left(\mathrm{CO}_{2}\right)$ by the $11 \mathrm{~mm}$ trocar until a pressure of $13 \mathrm{mmHg}$ was reached. The patients were operated on in the supine, neutral position, without the reverse Trendelemburg (RT) position, common in this type of surgery.

The variables obtained by transesophageal echocardiography were Cardiac Index $(\mathrm{Cl})$, Cardiac Output (CO) and Ejection Fraction (EF), in addition to the measurement of systolic blood pressure (SBP), diastolic blood pressure (DBP), mean arterial pressure (MAP) and heart rate (HR), recorded at three different times: before the onset of pneumoperitoneum ( $\mathrm{T} 1)$, ten minutes after $\mathrm{CO}_{2}$ insufflation (T2) and five minutes after deflation (T3).

We started with T1 before the onset of pneumoperitoneum to measure the baseline values of all patients, without any pneumoperitoneum interference. The T2 showed us the variables when the pneumoperitoneum was already established and the intra-abdominal pressure had already reached its plateau. Finally, with T3 measurements we wanted to obtain the values after a long period of pneumoperitoneum and also to be able to evaluate the difference of the hemodynamic values with and without the influence of the $\mathrm{CO}_{2}$ pressure in the peritoneal cavity.

We used the paired t-test for statistical analysis of the hemodynamic variations at the different moments. For statistical analysis, comparison and discussion of results, we display the results in mean and standard deviation (SD).

\section{RESULTS}

Of the 31 patients studied, nine were female, and 22, male. The mean age was 67.2 years. Three patients were classified as ASA I, and 28, as ASA II. Among the latter, 22 (71\%) had only one comorbidity (systemic arterial hypertension - SAH); five (16.1\%) had two (SAH and type-2 diabetes mellitus - DM); and one (3.2\%) had three (SAH, DM and arthrosis) (Table 1). 
Table 1. Patients' Characteristics.

Characteristics

\section{Gender}

$\begin{array}{lcc}\text { Male } & 9 & 29.0 \% \\ \text { Female } & 22 & 71.0 \%\end{array}$

Age

$\begin{array}{ccc}60-69 & 22 & 71.0 \% \\ 70-79 & 9 & 29.0 \%\end{array}$

ASA

$\begin{array}{ccc}\text { I } & 3 & 9.7 \% \\ \text { II } & 28 & 90.3 \%\end{array}$

Number od comorbidities

\begin{tabular}{ccc}
0 & 3 & $9.7 \%$ \\
1 & 22 & $71.0 \%$ \\
2 & 5 & $16.1 \%$ \\
3 & 1 & $3.2 \%$ \\
\hline
\end{tabular}

We studied the normality of the hemodynamic variables in T1 (prior to pneumoperitoneum) using the Kolmogorov-Smirnov normality test. The descriptive statistics of hemodynamic parameters at T1 were: $\mathrm{SBP}=108.3 \pm 14.8 ; \quad \mathrm{DBP}=67.5 \pm 10.3 ; \quad \mathrm{MAP}=82.9 \pm 11.3$; $H R=64.1 \pm 12.6 ; \quad C O=4.14 \pm 1.33 ; \quad C l=2.49 \pm 0.81 ; \quad$ and $E F=66.7 \pm 10.4$. The $p$ value of the Kolmogorov-Smirnov normality test did not present statistical significance in any of the evaluated parameters.

After instilling the pneumoperitoneum, we observed a general small variation in the hemodynamic parameters, with little expressive clinical repercussion. The increase in systolic and diastolic blood pressure was minimal, although statistically significant in the case of $\operatorname{DBP}(p=0.014)$.

The mean SBPs at the different moments were $\quad(\mathrm{mmHg}): \quad \mathrm{T} 1=108.3 \pm 14.8 ; \quad \mathrm{T} 2=115.7 \pm 17.0$; and $T 3=111.6 \pm 14.4$. The variations found were: T2$\mathrm{T} 1=7.1 \pm 21.6$; and $\mathrm{T} 3-\mathrm{T} 2=-4.1 \pm 21.7$. Variations were not statistically significant, with $p$-value $=0.067$ and 0.301 , respectively.

The mean DBPs at the different moments were $\quad(\mathrm{mmHg}): \quad \mathrm{T} 1=67.5 \pm 10.3 ; \quad \mathrm{T} 2=73.6 \pm 12.4$; and $T 3=66.7 \pm 9.8$. The variations found were: T2$\mathrm{T} 1=6.2 \pm 13.2$; and $\mathrm{T} 3-\mathrm{T} 2=-6.9 \pm 12.3$. Variations were statistically significant, with p-value $=0.014$ and 0.004 , respectively (Figure 1 and Table 2).

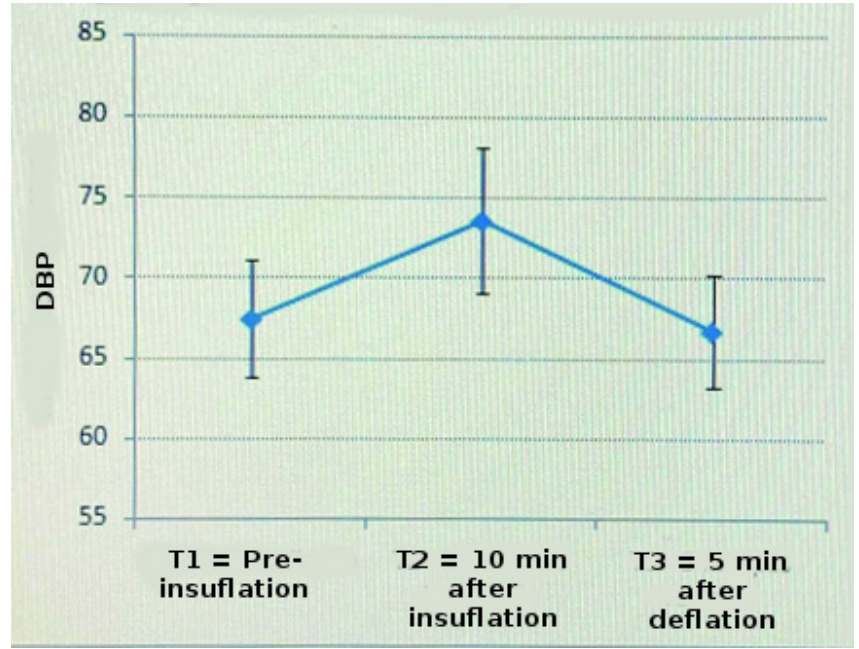

Figure 1. Mean and 95\% confidence interval of Diastolic Blood Pressure $(D B P)$ in $\mathrm{mmHg}$.

Table 2. Diastolic Blood Pressure (DBP) in $\mathrm{mmHg}$.

\section{Moment}

Statistic

$\mathrm{T} 1 \quad \mathrm{~T} 2=10 \mathrm{~min}$ pre-insufflation
$\mathrm{T} 2=10 \mathrm{~min} \quad \mathrm{~T} 3=5 \mathrm{~min}$ after insufflation
Variation in DBP

T2-T1

T3-T2

\begin{tabular}{lccccc}
\hline Mean & 67.5 & 73.6 & 66.7 & 6.2 & -6.9 \\
Standard deviation & 10.3 & 12.4 & 9.8 & 13.2 & 12.3 \\
p-value & & & 0.014 & 0.004 \\
\hline
\end{tabular}

The mean MAPs at the different moments were $(\mathrm{mmHg}): \mathrm{T} 1=82.9 \pm 11.3 ; \mathrm{T} 2=88.5 \pm 13.7 ; \quad$ and $\mathrm{T} 3=82.5 \pm 10.7$. The variations found were: T2-
$\mathrm{T} 1=5.6 \pm 17.5$; and $\mathrm{T} 3-\mathrm{T} 2=-6.0 \pm 16.7$. Variations were not statistically significant, with $p$ value $=0.082$ and 0.054 , respectively. 
The mean HRs, in beats per minute (bpm), at the different times were: $\mathrm{T} 1=64.1 \pm 12.6 ; \mathrm{T} 2=64.0 \pm 13.3$; and $T 3=65.7 \pm 8.3$. The variations found were: $T 2-T 1=$ $-0.1 \pm 14.2$; and $\mathrm{T} 3-\mathrm{T} 2=1.7 \pm 11.0$. Variations were not statistically significant, with $p$-value $=0.960$ and 0.393 , respectively.

The mean COs, in $\mathrm{ml} / \mathrm{min}$, at the different moments were: $\mathrm{T} 1=4.4 \pm 1.33 ; \mathrm{T} 2=4.26 \pm 1.39 ;$ and $\mathrm{T} 3=4.42 \pm 1.18$. The variations found were: T2$\mathrm{T} 1=0,13 \pm 1,23$; and $\mathrm{T} 3-\mathrm{T} 2=0.16 \pm 1.12$. Variations were not statistically significant, with $p$-value $=0.573$ and 0.442 , respectively.

The mean $\mathrm{Cls}$, in $\mathrm{L} / \mathrm{min} / \mathrm{m}^{3}$, at the different moments were: $\mathrm{T} 1=2.49 \pm 0.81 ; \quad \mathrm{T} 2=2.57 \pm 0.86$; and $T 3=2.66 \pm 0.73$. The variations found were: T2$\mathrm{T} 1=0.08 \pm 0.73$; and $\mathrm{T} 3-\mathrm{T} 2=0.09 \pm 0.66$. Variations were not statistically significant, with $p$-value $=0.527$ and 0.451 , respectively.

The mean EFs, in percentage (\%), in the different moments were: $\mathrm{T} 1=66.7 \pm 10.4 ; \mathrm{T} 2=63.2 \pm 9.9$; and $T 3=68.1 \pm 8.4$. The variations found were: $T 2-T 1=$
$-3.5 \pm 8.8 ;$ and $\mathrm{T} 3-\mathrm{T} 2=4.9 \pm 8.9$. Although small, the decrease in ejection fraction was statistically significant, decreasing $5.24 \%(p=0.035)$ in the variation of T2-T1. And in the period after $\mathrm{CO}_{2}$ deinsufflation the ejection fraction increased again ( $p=0.005$ ) (Figure 2 and Table 3).

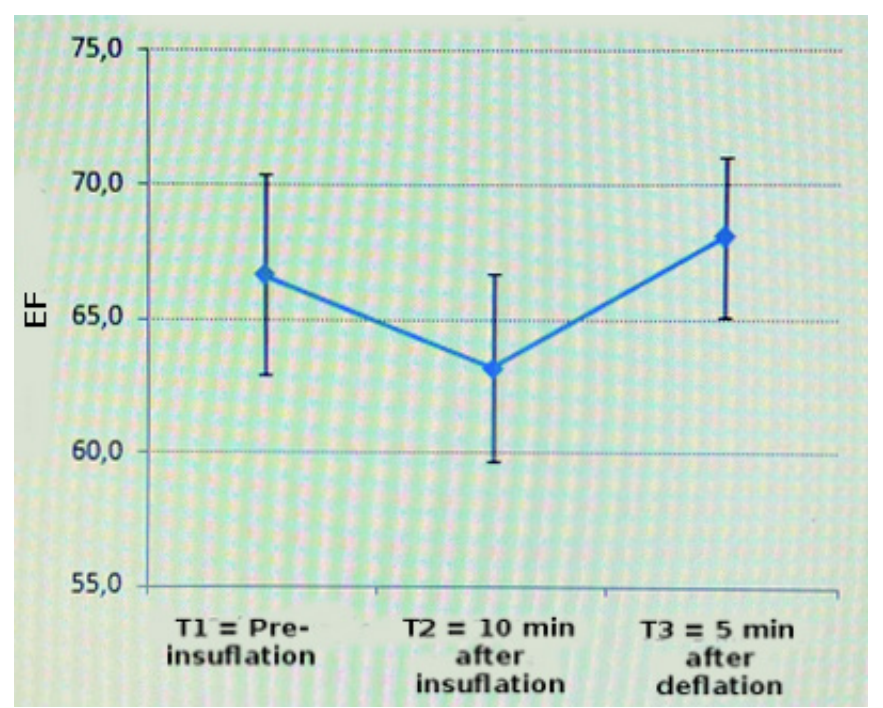

Figure 2. Mean and 95\% confidence interval of Ejection Fraction (EF) in $\%$.

Table 3. Eject fraction (EF) in \%.

\begin{tabular}{lccccc}
\hline \multicolumn{1}{c}{ Statistic } & $\begin{array}{c}\text { Moment } \\
\text { pre-insufflation }\end{array}$ & $\begin{array}{c}\text { T2=10 min } \\
\text { after insufflation }\end{array}$ & $\begin{array}{c}\text { T3=5 min } \\
\text { after deflation }\end{array}$ & T2-T1 & T3-T2 \\
\hline Mean & 66.7 & 63.2 & 68.1 & -3.5 & 4.9 \\
Standard deviation & 10.4 & 9.9 & 8.4 & 8.8 & 8.9 \\
p-value & & & & 0.035 & 0.005 \\
\hline
\end{tabular}

Table 4 shows the averages of the study variables being compared at the different moments.

Table 4. Mean results at the different times.

p-value

\begin{tabular}{lccccccc} 
Statistic/Moment & T1 & T2 & T3 & T2-T1 & T3-T2 & T2-T1 & T3-T2 \\
\hline PAS mmHg & 108.3 & 115.7 & 111.6 & 7.4 & -4.1 & 0.067 & 0.301 \\
DBP mmHg & 67.5 & 73.6 & 66.7 & 6.2 & -6.9 & 0.014 & $0.004^{*}$ \\
MAP mmHg & 82.9 & 88.5 & 82.5 & 5.6 & -6.00 & 0.082 & 0.054 \\
HR bpm & 64.1 & 64.00 & 65.7 & -0.1 & 1.7 & 0.96 & 0.393 \\
$\mathrm{CO} \mathrm{ml} / \mathrm{min}$ & 4.14 & 4.26 & 4.42 & 0.13 & 0.16 & 0.573 & 0.442 \\
$\mathrm{CI} \mathrm{L/min/m}$ & 2.49 & 2.57 & 2.66 & 0.08 & 0.09 & 0.527 & 0.451 \\
EF \% & 66.7 & 63.2 & 68.1 & -3.5 & 4.9 & 0.035 & $0.005^{*}$ \\
\hline
\end{tabular}

* Statistical significance. 


\section{DISCUSSION}

Despite the already recognized advantages of $L C$ in relation to conventional surgery ${ }^{10}$, pneumoperitoneum leads to cardiovascular alterations that are well tolerated by healthy individuals, but can be a threat to patients with comorbidities, frequent in the elderly. Several studies have demonstrated hemodynamic changes during laparoscopic cholecystectomy, with conflicting results ${ }^{11-14}$. Joris et al. ${ }^{14}$ showed that in healthy young patients the combined effects of anesthesia, Reverse Trendelemburg position and pneumoperitoneum lead to a $50 \%$ decrease in cardiac index associated with increased MAP and systemic vascular resistance (SVR). The same changes were presented by Mc Laughlin et al. ${ }^{15}$ in similar work, with a significant reduction of the CO. Nevertheless, in this same age group, there are studies that did not show any change in $\mathrm{CO}^{16}$, MAP, HR or $\mathrm{EF}^{9}$. Similarly, several works with elderly individuals also showed no significant changes in hemodynamic parameters during pneumoperitoneum. Dhoste et al. ${ }^{17}$ conclude that gradual abdominal insufflation up to $12 \mathrm{mmHg}$, followed by a 10-degree tilt in the RT position, do not alter cardiovascular stability, while maintaining CO, in elderly ASA III patients. Joshi et al. ${ }^{7}$ evaluated patients with mean age of 67 years through TEE monitoring during laparoscopic cholecystectomy, and despite having observed increased MAP and SVR, did not find a change in the ejection fraction. Cunningham et al. ${ }^{12}$, similarly, also did not observe any change in this parameter and suggest that the ventricular function remains preserved.

A recent study composed of young and elderly patients submitted to LC concluded that this surgery induces significant hemodynamic changes caused mostly by $\mathrm{CO}_{2}$ insufflation, and that the higher the established intra-abdominal pressure the higher the level of hemodynamic variation and the absorption of $\mathrm{CO}_{2}$ by the peritoneum ${ }^{18}$. However, only the variations of the MAP, PAS and HR, were evaluated in this study, insufficient data for such affirmations. In our study, we did not observe great variation in MAP, $\mathrm{CO}$ and $\mathrm{Cl}$. The EF changed slightly with pneumoperitoneum, falling 5.24\% $(p=0.035)$ (Figure 2$)$ in relation to the period before $\mathrm{CO}_{2}$ insufflation, which clinically did not mean much. However, it is worth emphasizing that in patients with compromised ventricular function, this alteration may represent a threat.

The main causes of hemodynamic changes during laparoscopic cholecystectomy are the mechanical compression of the pneumoperitoneum, the absorption of $\mathrm{CO}_{2}$, and the establishment of the reverse Trendelemburg (RT) position, being difficult to determine the contribution of each of these factors to these alterations ${ }^{12}$. Decreased preload, increased afterload and systemic release of humoral factors are associated with these changes ${ }^{19}$. In this study the patients were operated in neutral position and the result shows timid changes in the cardiac function during pneumoperitoneum. It is noteworthy that the calibration at time $\mathrm{T} 2$ occurred only ten minutes after the start of the pneumoperitoneum and, therefore, with minimal $\mathrm{CO}_{2}$ absorption until then. These findings may suggest that the RT position has a greater role in the hemodynamic changes than the pneumoperitoneum does. Other authors have already suggested the same ${ }^{19}$. Still in the same line, Dorsay et $a / .^{20}$ stated that the pneumoperitoneum alone has minimal hemodynamic effects, and that the RT position would be responsible, in their study, for the decrease in $\mathrm{CO}$, having the decrease in venous return as etiology.

We can conclude that laparoscopic laparoscopic cholecystectomy leads to hemodynamic changes, which are mostly discrete and clinically poorly expressive, and are well tolerated in elderly patients. Elderly patients with compromised ventricular function may be at increased risk during laparoscopic surgery due to decreased ejection fraction. The effect of $\mathrm{CO}_{2}$ insufflation on hemodynamic changes alone was not significant. There may be a greater contribution of the RT position in hemodynamic aleterations than of the pneumoperitoneum instillation. In the present study, only changes in diastolic blood pressure (DBP) and ejection fraction (EF) were statistically significant. There was no statistical correlation between hemodynamic variations, age and number of patients' comorbidities. 


\title{
R E S U M O
}

\begin{abstract}
Objetivo: demonstrar as alterações hemodinâmicas durante a colecistectomia laparoscópica em pacientes idosos com auxílio da ecocardiografia trans-esofágica Métodos: foram estudados trinta e um pacientes idosos (com 60 anos de idade ou mais), ASA I ou II, submetidos à colecistectomia laparoscópica eletiva, sob anestesia geral padronizada, com aferição de parâmetros cardiovasculares através de ecocardiograma trans-esofágico em três momentos diferentes: antes do pneumoperitônio (T1), após a insuflação do $\mathrm{CO}_{2}$ (T2) e na desinsuflação (T3). As variações da pressão arterial sistólica, diastólica e média, da frequência cardíaca, do débito e do índice cardíaco, e da fração de ejeção foram avaliadas estatisticamente. Resultados: apesar de pequenas, somente as variações da pressão arterial diastólica (PAD) e da fração de ejeção (FE) foram estatisticamente significativas. A PAD, em mmHg, nos diferentes momentos, de acordo com a média e desvio padrão, foram: $T 1=67,5 \pm 10,3 ; T 2=73,6 \pm 12,4 ; T 3=66,7 \pm 9,8$. E para a $\mathrm{FE}$, em porcentagem (\%), nos diferentes momentos, de acordo com média e desvio padrão, foram: $T 1=66,7 \pm 10,4 ; T 2=63,2 \pm 9,9 ; T 3=68,1 \pm 8,4$. Não houve correlação estatística entre as variações hemodinâmicas, a idade e número de comorbidades dos pacientes. Conclusão: a colecistectomia laparoscópica causa poucas alterações hemodinâmicas que são bem toleradas pela maioria dos pacientes idosos; o comprometimento prévio da função ventricular representa ameaça em pacientes idosos durante a cirurgia; parece haver menor efeito hemodinâmico causado pelo pneumoperitônio do que pelo posicionamento do paciente em Trendelemburg reverso durante a cirurgia.
\end{abstract}

Descritores: Pressão Arterial. Hemodinâmica. Ecocardiografia Transesofagiana. Idoso. Laparoscopia. Pneumoperitônio Artificial.

\section{REFERENCES}

1. Loureiro ER, Klein SC, Pavan CC, Almeida LD, da Silva FH, Paulo DN. Laparoscopic cholecystectomy in 960 elderly patients. Rev Col Bras Cir. 2011;38(3):155-9.

2. Yetkin G, Uludag M, Oba S, Citgez B, Paksoy I. Laparoscopic cholecystectomy in elderly patients. JSLS. 2009;13(4):587-91.

3. Tagle FM, Lavergne J, Barkin JS, Unger SW. Laparoscopic cholecystectomy in the elderly. Surg Endosc. 1997;11(6):636-8.

4. Annamaneni RK, Moraitis D, Cayten CG. Laparoscopic cholecystectomy in the elderly. JSLS. 2005;9(4):40810.

5. Yaman C, Renner S, Binder H, Oppelt P. Laparoscopy in elderly women. J Gynecol Surg. 2009;25(2):61-6.

6. Zhu Q, Mao Z, Jin J, Deng Y, Zheng M, Yu B. The Safety of $\mathrm{CO}_{2}$ pneumoperitoneum for elderly patients during laparoscopic colorectal surgery. Surg Laparosc Endosc Percutan Tech. 2010;20(1):54-7.

7. Joshi GP, Hein HA, Mascarenhas WL, Ramsay MA, Bayer O, Klotz P. Continuous transesophageal echoDoppler assessment of hemodynamic function during laparoscopic cholecystectomy. J Clin Anesth. 2005;17(2):117-21.

8. Goodale RL, Beebe DS, McNevin MP, Boyle M, Letourneau JG, Abrams JH, et al. Hemodynamic, respiratory, and metabolic effects of laparoscopic cholecystectomy. Am J Surg. 1993;166(5):533-7.
9. D'Ugo D, Persiani R, Pennestri F, Adducci E, Primieri $P$, Pende $V$, et al. Transesophageal echocardiographic assessment of hemodynamic function during laparoscopic cholecystectomy in healthy patients. Surg Endosc. 2000;14(2):120-2.

10. Efron DT, Bender JS. Laparoscopic surgery in older adults. J Am Geriat Soc. 2001;49(5):658-63.

11. Critchley LA, Critchley JA, Gin T. Haemodynamic changes in patients undergoing laparoscopic cholecystectomy: measurement by transthoracic electrical bioimpedance. $\mathrm{Br} J$ Anaesth. 1993;70(6):681-3.

12. Cunningham AJ, Turner J, Rosenbaum S, Rafferty T. Transoesophageal echocardiographic assessment of haemodynamic function during laparoscopic cholecystectomy. Br J Anaesth. 1993;70(6):621-5.

13. Carter JF, Chang EY, Haynes G, Scardo JA. Hemodynamic effects of pneumoperitoneum during gynecologic laparoscopic surgery. J Gynecol Surg. 1997;13(4):169-73.

14. Joris JL, Noirot DP, Legrand MJ, Jacquet NJ, Lamy ML. Hemodynamic changes during laparoscopic cholecystectomy. Anesth Analg. 1993;76(5):106771.

15. McLaughlin JG, Seheeres DE, Dean RJ, Bonnell BW. The adverse hemodynamic effects of laparoscopic cholecystectomy. Surg Endosc. 1995;9(2):121-4.

16. Larsen JF, Svendsen FM, Pedersen V. Randomized clinical trial of the effect of pneumoperitoneum 
on cardiac function and haemodynamics during laparoscopic cholecystectomy. $\mathrm{Br} J$ Surg. 2004;91(7):848-54.

17. Dhoste K, Lacoste L, Karayan J, Lehuede MS, Thomas D, Fusciardi J. Haemodynamic and ventilatory changes during laparoscopic cholecystectomy in elderly ASA III patients. Can J Anesth. 1996;43(8):783-8.

18. Umar A, Mehta KS, Mehta N. Evaluation of hemodynamic changes using different intra-abdominal pressures for laparoscopic cholecystectomy. Indian J Surg. 2013;75(4):284-9.

19. Hirvonen EA, Poikolainen EO, Pääkkönen ME, Nuutinen LS. The adverse hemodynamic effects of anesthesia, head-up tilt, and carbon dioxide pneumoperitoneum during laparoscopic cholecystectomy. Surg Endosc. 2000;14(3):272-7.
20. Dorsay DA, Greene FL, Baysinger CL. Hemodynamic changes during laparoscopic cholecystectomy monitored with transesophageal echocardiography. Surg Endosc. 1995;9(2):128-33; discussion 133-4.

Received in: 08/12/2017

Accepted for publication: 1\%02/2018

Conflict of interest: none.

Source of funding: none.

Mailing address:

Antônio Carlos Iglesias

E-mail: aciglesias.If@gmail.com /

joseantoniocunha@yahoo.com.br

(cc) BY 